\title{
ON MOVEMENTS RESULTING FROM FARADIC EXCITÁTION OF THE CORPUS CALLOSUM IN MONKEYS.
}

BY F. W. MOTT, M.D. AND E. A. SCHARFER, F.R.S.

(Froin the Physiologioal Laboratory, Univorsity Collego, London.)

If a pair of fine electrodes, guarded except at the extremity with shellac or paraffin, are carefully passed vertically into the great longitudinal fissure between the hemispheres and are thus used to stimulate the upper surface of the corpus callosum, bilateral movements of the head, trunk and limbs are obtained according to the point to which the electrodes are applied. These movements are due to excitation of fibres in the corpus callosum and not to a spreading of the electric currents to the "motor" surface of the cortex, for (1) the effects are obtained with very weak currents, and (2) if the electrodes are somewhat withdrawn from the surface of the corpus callosum the effects immediately cease, although the excitation is unw applied at a point nearer the motor surface.

The effects ure obtained, roughly speaking, in the following order from before back, viz.:-When the electrodes are applied over and just behind the genu, head and eye movements are produced ; further back, movements of the arms at the shoulder and of the upper part of the trunk; then movements of the forearms and general movements of the hands and fingers; then of the lower part of the trunk and tail, and lastly, movements of the lower limbs. The movements are not obtained if the anæthesia be too deep; they become uniiateral if the grey " motor" cortex of one hemisphere be destroyed by actnal cautery. and if the excitation be too strong or too prolonged they pass into epileptoid contractions: they are evidently due therefore to indirect excitation of the 
"motor" cortical centres. Although movements of particular parts of the body are thus roughly or generally capable of being produced by excitation of different parts of the corpus callosum the localization is not exact, for there are usually other movements produced at the same time but less markedly, as if the fibres going to the several cortical areas, although more massed at certain parts of the corpus callosum, are yet scattered over a considerable length of the commissure. This is in conformity with the degeneration results obtained in the corpus callosum by Sherrington, after anilateral destruction of localized portions of the " motor" area."

In order to investigate more precisely. the position of these fibres in the corpus callosum we have in several experiments cut away one hemisphere and directly excited the cut surface of the corpas callosum. The movements then obtained are of course confined to the side of the body which is in nervous connection with the intact hemisphere, that is to say, if the left hemisphe $e_{1}$ be cut away, the movements are on the left side of the body.

Operating in this muwner we have been able to obtain mach more distinct and specialized movements than when the intact commissure is stimulated at the bottom of the longitudinal fissure, but the experiment is far more difficult to perform in this way, and is frequently entirely vitiated by the profuse hæmorrhage which usually follows the removal. The genersl results are, however, the same. Movements of the eyes and head are got most anteriorly, of the lower limb most posteriorly; and of the upper limb and trunk between. With the weakest possible excitation, a favourable slight condition of narcosis, and a freshly-made section of the commissure we have occasionally obtained very precisely specialized movements, such as a simple conjugate lateral deviation of the eyes, simple opposition of the hallux and the like. These simple movements were, however, rarely got; asually although one part showed a greater tendency to move, other and even distant parts of the body might also but less strongly be set in action, thus indicating as before, a scattering of the commissural fibres. Even when the movements are confined

I Journal of Physiology, rol. 
to one part of the body or one limb, they are very seldom completely specialized, but are usually general movements. This is the case, not only when the cut surface is stimalated, but as might be supposed also when the excitation is applied from above to the intact corpus callosum. For instance, the flexors and extensors of a limb are often both thrown simultaneously into action, and the eye-movements instead of being definite movements of conjugate deviation are frequently indefinite or rolling movements. Nor, in the case of the stintulation of the intact corpus callosum, are the muscles which are called into action always quite the same on the two sides of the body, although those which are most strongly affected always belong to the same part. This may easily bo understood, if we consider that the bundles of fibres which pass within the corpus callosum to corresponding points in the grey cortex of the hemispheres would not necessarily cross at exactly the same point, for those passing to the one side might be placed more superficially or more anteriorly as compared with those passing to the other side : hence we should expect to find some differences in the movements of the two sides.

For some reason which we are unable to explain, we were never successful in obtaining contractions of the muscles of the face from stimulation of any part of the commissure. ${ }^{1}$

It is not improbable, however, that the commissural fibres for their motor centres (and perhaps also for those of the larynx) may yet be found in the rostrum of the corpus callosum. We certainly explored this part on two or three occasions, but the negative results we obtained may perhaps be ascribed to the hæmorrhage which accompanied its exposure. This may also account for the fact that we failed to get any movements on stimulating the spleniam, although we had expected to obtain morements of the eyes from its excitation. Practically all the results which we have obtained have been yielded by the thinner middle part or body of the great commissure. We have performed a con-

\footnotetext{
1 We vere also unsuccessful in obtaining any independent movements of the fingers, although wo once or twice obtained such movemeuts of the toes.
} 
siderable number of experiments and have employed for the parpose several different binds of monkey (Liponda, Rhoesus, Bonnet, Callithrix). The most precise evidence of localization within the commissure which we obtained in any was got from a fine, intelligent Bonnet; bat the conditions of experiment may have been accidentally favourable on this occasion. The sequence of movements obtained by stimulating the cut surface from before back was very distinct in this case and certain movements were easily isolable. In most other animals the movements were, as has been above mentioned, of mixed character, with occasional preponderance of movement of particular parts. Thus in one case retraction of the arm and shoulder, combined with flexion of the leg and hip, recurred as a prevalent action. In another case, in which we stimulated with flat paraffin-guarded electrodes successive points of the under surface of the corpus callosum, we obtained along the whole length of the excitable part, movements of the eyes and eyelids.

The general results of our experiments and the inferences which may be drawn from them are briefly the following:-

1. The corpus callosum contrins fibres excitation of which produces movements on both sides of the body.

2. These fibres do not pass directly from the corpas callosum to the internal cepsule ${ }^{1}$ but enter the grey cortex of the hemispheres, and there come into connection with the socalled "motor centres."

The fibres which pass to the severel mowr centres, although mainly massed in definite parts of the corpus callosum, are not confined entirely to those parts, but are to a certain extent scattered along the middle thinner part of the commissure.

\footnotetext{
1 When destruction of the grey cortex pras effected by actoal cantery, as befora described, cary was taken to aroid injuring any connection between the corpus callosum and the internal capsule.
} 